\title{
DINÂMICA MIGRATÓRIA NO ESTADO DO RIO DE JANEIRO PÓS-2010: O PERFIL DO IMIGRANTE LOCAL
}

\author{
MIGRATORY DYNAMICS IN RIO DE JANEIRO STATE POST 2010: THE PROFILE OF THE LOCAL IMMIGRANT
}

\section{RESUMO}

A partir dos microdados das PNADs de 2011 a 2015, o artigo analisa as matrizes migratórios interestaduais do Rio de Janeiro e realiza uma caracterização do perfil de seu imigrante. Os dados evidenciam que a crise econômico-financeira estadual deflagrada a partir de 2014 está associada a uma redução do saldo migratório estadual, cuja magnitude provavelmente não foi mais expressiva devido ao caráter inercial de seus fluxos migratórios (existência de redes de contato entre regiões de origem e destino e sua implicação para a redução dos riscos do deslocamento, especialmente em contextos de crise). Observa-se relativa seletividade (e estabilidade) no processo migratório: os imigrantes fluminenses tendem a ser homens, brancos, com situação conjugal estável e com elevados níveis de escolaridade. Há indícios de aumento da migração das mulheres e de indivíduos pretos e pardos, todavia, estas características ainda não são as mais beneficiadas pelo processo migratório.

Palavras-chave: Fatores de atração e retenção populacional; Imigração; Rio de Janeiro.

\section{ABSTRACT}

Based on the PNADs microdata (2011 to 2015), the paper analyzes the interstate migratory matrices of Rio de Janeiro and characterizes the immigrant profile. The analysis shows that the economic and financial crisis of 2014 is associated with a reduction in the state migration balance, whose magnitude was probably no longer significant due to the inertial nature of their migratory flows (existence of networks between regions of origin and destiny). Relative selectivity (and stability) is observed in the migratory process: immigrants tend to be white men, with stable marital status and with high levels of education. There is evidence of increased migration of women and black and brown individuals.

Keywords: Push and pull factors; Immigration; Rio de Janeiro.

\section{Ana Carolina da Cruz Lima ${ }^{a}$}

a Universidade do Estado do Rio de Janeiro (UERJ), Rio de Janeiro, RJ, Brasil

DOI: $10.12957 /$ geouerj.2020.47266

Correpondência: ana.lima@uerj.br

Recebido em: 13 set. 2019

Revisado em: 21 out. 2019

Aceito em: 12 dez. 2019 


\section{INTRODUÇÃO}

As migrações são parte integrante do processo socioeconômico e possuem uma regularidade observada sob a forma de fluxos (trajetórias), cuja importância para a dinâmica espacial assume caráter estrutural (BRITO, 2002, p.18). De forma geral, as trajetórias migratórias estão relacionadas ao processo de integração de mercados e funcionam como um mecanismo de transferência do excedente populacional de regiões pouco dinâmicas para economias urbano-industriais em expansão (BRITO, 2002). Os padrões migratórios influenciam e são influenciados por aspectos econômicos, sociais, políticos e demográficos, logo, são dinâmicos e tendem a perpetuar especificidades regionais (corroboram a irregularidade espacial do crescimento).

No caso do Brasil, até a década de 1970 as trajetórias migratórias dominantes ocorriam da região Nordeste e do estado de Minas Gerais para os estados de São Paulo e Rio de Janeiro, grandes receptores de migrantes devido a suas elevadas taxas de crescimento industrial e de geração de emprego (BRITO, 1997). Os fluxos tinham origem majoritariamente em áreas rurais e destinavam-se para áreas urbanas.

A partir da década de 1980, verifica-se um processo de transição migratória, com redução das trajetórias dominantes em prol de trajetórias secundárias, que representavam etapas dos fluxos principais. Houve, inclusive, aumento da migração de retorno. Baeninger (2008), Brito (2006), Brito e Carvalho (2006) e Lima et al. (2016) identificam a intensificação dos deslocamentos populacionais em direção a áreas tradicionalmente emissoras de migrantes e a consolidação de novos polos de absorção migratória, principalmente na região centro-sul do Brasil. As cidades médias desempenham importante função neste processo: o congestionamento urbano das grandes metrópoles torna mais difícil o ajustamento do migrante ao novo contexto social; em contrapartida, as cidades médias têm se tornado mais dinâmicas e gerado oportunidades de renda e emprego sem a ocorrência dos custos presentes das grandes aglomerações urbanas (insuficiência do sistema de transporte urbano, saneamento básico, educação, saúde, habitação etc.).

Sobre a expansão das trajetórias migratórias secundárias no Brasil, Lima et al. (2016) ressaltam que a velocidade destas mudanças está relacionada à sua complexa dinâmica socioeconômica: (i) os determinantes clássicos da migração (fatores de atração e repulsão populacional) influenciam fluxos migratórios das regiões mais pobres para as regiões mais ricas; e (ii) fatores relacionados às aspirações individuais estimulam novos tipos de deslocamentos, que não possuem uma relação linear e inversa com os níveis regionais de desenvolvimento urbano. Observa-se, conforme ressalta De Haas (2010), que aspectos estruturais e macroeconômicos condicionam as trajetórias migratórias nacionais, todavia, a capacidade individual de tomar decisões torna-se mais importante para a determinação dos deslocamentos populacionais.

Apesar das mudanças observadas, há um aspecto inercial nas trajetórias migratórias dominantes, destinadas às regiões que possuem níveis mais elevados de desenvolvimento econômico e renda per capita, 
que tendem a recuperar importância relativa em contextos de crise e estagnação econômica (LIMA et al., 2016). Nessa perspectiva, o objetivo do artigo é analisar a evolução e as principais características dos migrantes interestaduais cuja região de destino é o estado do Rio de Janeiro. Pretende-se observar se a crise econômico-financeira estadual, deflagrada na primeira metade da década de 2010, pode estar associada à redução da atratividade local e se houve mudanças no perfil do migrante local. A análise permitirá identificar se o estado do Rio de Janeiro mantém seu status de tradicional destino migratório no país. Serão utilizados os microdados da Pesquisa Nacional por Amostra de Domicílios (PNAD) do período 2011-2015 para caracterizar o perfil do migrante e calcular as matrizes migratórias interestaduais do período.

$\mathrm{O}$ artigo possui quatro seções. Na primeira, é realizada uma análise do padrão migratório brasileiro no período 2000/2010 com o intuito de enfatizar a importância relativa do Rio de Janeiro como região absorvedora de população. Na segunda seção, são apresentadas matrizes migratórias com o intuito de verificar a evolução da capacidade de atração e retenção populacional do Rio de Janeiro. Na terceira seção, são descritas as características da amostra e é determinado o perfil do migrante residente no estado do Rio de Janeiro. Em seguida são realizadas as considerações finais.

\section{O padrão migratório nacional entre 2000 e 2010}

Na primeira metade da década de 2000, a economia brasileira adotou uma série de reformas e ajustes institucionais, essenciais para a consolidação da estabilidade macroeconômica (WERNECK, 2014). O principal objetivo das políticas econômicas era a manutenção das expectativas dos agentes financeiros em relação às regras implementadas no final dos anos 1990 (câmbio flutuante, metas de inflação e de superávit primário), garantindo, assim, a credibilidade do país no mercado internacional. A segunda metade da década é caracterizada pela estabilidade de preços, retomada dos investimentos públicos em infraestrutura (energia, transportes, habitação popular etc.), via Plano de Aceleração do Crescimento (PAC), e adoção de políticas sociais de combate à pobreza (WERNECK, 2014). ${ }^{1}$

A implementação dessas medidas, em um contexto externo favorável (boom de commodities) e mediante a existência de capacidade ociosa, estimulou o aumento da demanda interna e a expansão econômica (efeitos multiplicadores sobre a produção, o emprego e a renda), cuja taxa média de crescimento entre 2006 e 2009 foi de aproximadamente 3,7\% (IPEA, 2010). Houve, inclusive, aumento da quantidade de pessoas ocupadas e redução da informalidade. Todavia, após a crise financeira internacional de 2009, 0 esgotamento das condições externas favoráveis e alterações expressivas no cenário interno (i.e. redução de

\footnotetext{
${ }^{1}$ A estratégia adotada para minimizar as disparidades sociais no país baseou-se no aumento do valor real do salário mínimo e na ampliação dos gastos públicos destinados a aposentadorias e pensões e às transferências de recursos para famílias de baixa renda (BARROS et al., 2010).
} 
capacidade ociosa e distanciamento das metas de superávit fiscal e de inflação) evidenciavam a necessidade de implementação de reformas estruturais na economia brasileira, relacionadas principalmente à infraestrutura de oferta (educação, produtividade, poupança etc.), e o caráter conjuntural do ciclo expansionista (GIAMBIAGI e PINHEIRO, 2012).

Ressalta-se que no período as regiões menos desenvolvidas do país cresceram a taxas superiores à média nacional, contudo, seus indicadores socioeconômicos permaneceram desfavoráveis, o que demonstra a relativa estabilidade da dinâmica regional brasileira (a atividade produtiva continua concentrada em poucas regiões e setores e há expressivas heterogeneidades inter e intrarregionais) (LIMA et al., 2016). Neste cenário, as cidades médias emergiram como importantes polos de desenvolvimento urbano não metropolitano (REGIC, 2008).

As tendências da economia brasileira entre 2000 e 2010 impactaram os movimentos migratórios de sua população em diferentes perspectivas. Por um lado, as taxas de crescimento mais elevadas verificadas em suas regiões mais pobres funcionaram como fatores de retenção populacional nas regiões de origem dos migrantes e estimularam um contrafluxo migratório (de retorno ou não); por outro, a retomada do crescimento (ou ao menos a estabilidade) nas regiões centrais do país (centro-sul) estimulou a atração de indivíduos que buscam oportunidades de renda e emprego e/ou a manutenção de padrões anteriores.

A Tabela 1 apresenta informações gerais sobre as migrações internas no Brasil entre 2000 e 2010 a partir dos microdados do Censo Demográfico 2010. A matriz migratória interestadual por UF pode ser consultada na Tabela A1 do Apêndice. A análise da matriz permite identificar as principais regiões de origem e destino dos migrantes internos no Brasil, demonstrando quais trajetórias são mais significativas.

A análise e a interpretação dos dados evidenciam o recrudescimento da importância das trajetórias migratórias secundárias (regionais) no país, ainda que o enfraquecimento dos fluxos dominantes ocorra em ritmo não muito expressivo. A consolidação de aglomerações urbanas metropolitanas e não metropolitanas ao longo dos últimos anos foi essencial para este processo (BAENINGER, 2008). O crescimento das cidades médias e a periferização dos grandes centros urbanos estimularam deslocamentos em sua direção, de tal forma que a migração para as grandes metrópoles diminuiu em prol das regiões urbanas não metropolitanas (BRITO, 2006). Esta expansão estimulou a atratividade destas regiões (migração da mão de obra), o que contribuiu para a elevação de suas taxas de crescimento demográfico no período analisado.

Em contrapartida, a manutenção das disparidades regionais continua a limitar a expansão das trajetórias migratórias secundárias no país. O padrão migratório dominante no Brasil (Nordeste-Sudeste) é caracterizado por sua elevada inter-relação com a questão regional brasileira. Além disso, este padrão possui um componente inercial, estimulado pelas redes de contato entre migrantes e não migrantes, residentes, 
respectivamente, nos destinos e nas origens. Estas características tornam mais difíceis alterações nestes padrões, pois quaisquer melhorias socioeconômicas nos tradicionais destinos dos migrantes internos brasileiros tendem a manter e/ou reforçar a atratividade destas regiões.

Tabela 1. Migração interna por estado (Brasil, 2010) Fonte: elaboração própria a partir dos microdados dos Censos Demográficos 2010. Fonte: elaboração própria a partir dos microdados dos Censos Demográficos 2010. OBS: critério migratório é data fixa (05 ano antes da data de recenseamento).

\begin{tabular}{|c|c|c|c|c|c|c|c|}
\hline & \multicolumn{3}{|c|}{ Migração interestadual } & \multirow[b]{2}{*}{$(\%)$} & \multirow[b]{2}{*}{ Saldo* } & \multicolumn{2}{|c|}{ Migração de retorno } \\
\hline & Imigrantes & (\%) & Emigrantes & & & Interestadual & (\%) \\
\hline RO & 27.371 & $1,56 \%$ & 19.495 & $1,11 \%$ & 7.876 & 1.756 & $0,39 \%$ \\
\hline$A C$ & 5.682 & $0,32 \%$ & 5.168 & $0,30 \%$ & 514 & 790 & $0,18 \%$ \\
\hline AM & 26.587 & $1,52 \%$ & 19.587 & $1,12 \%$ & 7.000 & 2.517 & $0,56 \%$ \\
\hline $\mathrm{RR}$ & 9.100 & $0,52 \%$ & 4.565 & $0,26 \%$ & 4.535 & 539 & $0,12 \%$ \\
\hline PA & 58.551 & $3,34 \%$ & 66.026 & $3,77 \%$ & -7.475 & 9.968 & $2,23 \%$ \\
\hline AP & 11.693 & $0,67 \%$ & 5.277 & $0,30 \%$ & 6.416 & 839 & $0,19 \%$ \\
\hline TO & 29.899 & $1,71 \%$ & 25.793 & $1,47 \%$ & 4.106 & 4.709 & $1,06 \%$ \\
\hline MA & 38.869 & $2,22 \%$ & 74.616 & $4,26 \%$ & -35.747 & 18.031 & $4,04 \%$ \\
\hline $\mathrm{PI}$ & 26.461 & $1,51 \%$ & 43.938 & $2,51 \%$ & -17.477 & 13.518 & $3,03 \%$ \\
\hline CE & 44.752 & $2,56 \%$ & 57.405 & $3,28 \%$ & -12.653 & 24.553 & $5,50 \%$ \\
\hline RN & 27.787 & $1,59 \%$ & 20.335 & $1,16 \%$ & 7.452 & 9.753 & $2,19 \%$ \\
\hline PB & 37.904 & $2,17 \%$ & 39.978 & $2,28 \%$ & -2.074 & 18.564 & $4,16 \%$ \\
\hline PE & 57.958 & $3,31 \%$ & 78.011 & $4,46 \%$ & -20.053 & 25.788 & $5,78 \%$ \\
\hline $\mathrm{AL}$ & 21.639 & $1,24 \%$ & 40.812 & $2,33 \%$ & -19.173 & 9.932 & $2,23 \%$ \\
\hline SE & 20.459 & $1,17 \%$ & 15.281 & $0,87 \%$ & 5.178 & 5.989 & $1,34 \%$ \\
\hline BA & 91.077 & $5,20 \%$ & 146.647 & $8,38 \%$ & -55.570 & 40.874 & $9,16 \%$ \\
\hline MG & 148.893 & $8,51 \%$ & 151.682 & $8,66 \%$ & -2.789 & 53.166 & $11,92 \%$ \\
\hline ES & 52.255 & $2,99 \%$ & 28.027 & $1,60 \%$ & 24.228 & 8.497 & $1,90 \%$ \\
\hline RJ & 102.629 & $5,86 \%$ & 115.413 & $6,59 \%$ & -12.784 & 22.034 & $4,94 \%$ \\
\hline SP & 327.454 & $18,71 \%$ & 313.819 & $17,93 \%$ & 13.635 & 59.402 & $13,32 \%$ \\
\hline$P R$ & 109.398 & $6,25 \%$ & 119.978 & $6,85 \%$ & -10.580 & 39.066 & $8,76 \%$ \\
\hline SC & 122.692 & $7,01 \%$ & 55.559 & $3,17 \%$ & 67.133 & 17.830 & $4,00 \%$ \\
\hline RS & 44.833 & $2,56 \%$ & 83.287 & $4,76 \%$ & -38.454 & 20.271 & $4,54 \%$ \\
\hline MS & 42.971 & $2,45 \%$ & 33.370 & $1,91 \%$ & 9.601 & 7.029 & $1,58 \%$ \\
\hline MT & 57.463 & $3,28 \%$ & 47.751 & $2,73 \%$ & 9.712 & 3.651 & $0,82 \%$ \\
\hline GO & 133.011 & $7,60 \%$ & 61.687 & $3,52 \%$ & 71.324 & 20.847 & $4,67 \%$ \\
\hline DF & 73.181 & $4,18 \%$ & 77.062 & $4,40 \%$ & -3.881 & 6.136 & $1,38 \%$ \\
\hline Brasil & 1.750 .569 & $100 \%$ & 1.750 .569 & $100 \%$ & - & 446.049 & $100 \%$ \\
\hline
\end{tabular}

As trajetórias observadas a partir das matrizes migratórias interestaduais de 2010 evidenciam os deslocamentos individuais resultantes destas duas tendências principais. A maior proporção de imigrantes continua a se direcionar para as localidades responsáveis pela maior parcela da renda nacional. Estas regiões localizam-se majoritariamente nos estados de São Paulo e do Rio de Janeiro, porém, cresce a importância dos destinos situados em Minas Gerais, Paraná, Goiás e Santa Catarina. Simultaneamente, as regiões de origem destes indivíduos tornaram-se mais dispersas, sendo possível observar a diminuição da emigração de áreas que tradicionalmente expulsavam suas populações, como Minas Gerais, Paraná e alguns estados da região Nordeste. 
Observa-se que o estado do Rio de Janeiro apresentou saldo migratório negativo no período intercensitário. Esse resultado está vinculado à elevação da atratividade de regiões de médio porte e à redução da atratividade dos grandes centros urbanos metropolitanos. Por exemplo, a principal microrregião deste estado, a Região Metropolitana do Rio de Janeiro, apresentou uma diminuição dos imigrantes e um aumento dos emigrantes (redução das capacidades de atração e retenção populacional), cujo resultado mais expressivo foi a elevação de suas perdas migratórias. Em contrapartida, outras regiões do estado, como Macaé, Três Rios, Campos dos Goytacazes, Lagos, Barra de São João, Ilha Grande e Itaguaí, atraíram uma quantidade mais elevada de imigrantes, evitando, assim, uma redução mais expressiva do saldo migratório estadual.

As regiões fluminenses atraem indivíduos de todas as regiões do país, cujas origens estão localizadas principalmente em São Paulo, Minas Gerais, Nordeste (Bahia, Paraíba, Ceará e Pernambuco)², Brasília, Rio Grande do Sul e Pará. Houve, inclusive, um pequeno aumento da migração de retorno para o Rio de Janeiro (volta de naturais para o estado). Os principais destinos dos migrantes do Rio de Janeiro estão localizados em São Paulo, Minas Gerais, Espírito Santo, Bahia, Paraíba, Pernambuco, Ceará e Brasília. Nos dois primeiros casos, os emigrantes dirigem-se para regiões variadas destes estados; nos demais, o deslocamento ocorre principalmente em direção a regiões polarizadas pelas capitais estaduais e relaciona-se ao retorno individual.

Os fluxos migratórios de e para o Rio de Janeiro são um indício de que a estabilidade econômica da década de 2000 contribuiu para diminuir o ritmo de expansão de mudanças espaciais mais amplas nos padrões migratórios brasileiros. Em um cenário menos incerto, em termos de oportunidades de emprego, e de expansão de programas sociais, em especial de transferência de renda, a efetivação da migração para áreas cujo histórico de crescimento econômico é favorável envolve menos riscos. O caráter inercial do padrão migratório dominante no Brasil favorece, em alguma medida, a expansão dos fluxos migratórios para regiões polarizadas por cidades médias destes estados. Em outras palavras, as perdas da Região Metropolitana do Rio de Janeiro ocorreram, principalmente, em prol de cidades médias vizinhas a esta região. O redirecionamento dos deslocamentos populacionais para outros estados é, neste sentido, limitado pela elevada capacidade de atração das regiões que historicamente impulsionam o desenvolvimento da economia brasileira.

Este fato não interrompeu completamente as transformações nas trajetórias migratórias secundárias. Diversas localidades dos demais estados da região centro-sul do país ganharam importância como novos destinos dos migrantes. A dinamização destas regiões, viabilizada pela continuidade da desconcentração das atividades produtivas e pelo crescimento das cidades médias, estimulou as capacidades locais de atração e retenção populacional. Além disso, áreas dinâmicas isoladas nas regiões Norte e Nordeste tiveram um aumento dos seus níveis de atratividade populacional.

\footnotetext{
${ }^{2}$ As origens nestes estados tornam-se cada vez mais dispersas devido à facilidade de deslocamento direto para o Rio de Janeiro, viabilizada pela continuidade da redução dos custos de transporte no país.
} 
Vale salientar o arrefecimento da migração de retorno interestadual para áreas menos desenvolvidas e o aumento do retorno para áreas mais desenvolvidas, fenômenos provavelmente associados ao desempenho dos mercados de trabalho nessas localidades. Essa tendência evidencia a dificuldade que existe para quebrar o componente inercial das trajetórias dominantes no país. Mesmo em um contexto de expansão mais acelerada do emprego e da renda em regiões periféricas, os indivíduos podem optar por migrar ou continuar em áreas de crescimento (médio) mais estável.

Em resumo, as mudanças ocorridas nos deslocamentos da população brasileira nos últimos anos apontam para um período transitório, que aos poucos procura romper o caráter inercial de seu padrão dominante (nordeste-sudeste). Todavia, esse processo não é linear, pois a retomada do crescimento e a estabilidade econômica nos anos 2000 auxiliaram a recompor os fluxos dominantes, diminuindo assim o ritmo de expansão da transição migratória brasileira. Percebe-se que as inter-relações entre desenvolvimento e migração e a persistência das elevadas disparidades regionais no Brasil tendem a reforçar o caráter inercial deste fluxo, limitando a velocidade das mudanças que ocorrem em suas trajetórias migratórias secundárias/regionais. Mais especificamente, os dados evidenciam que as alterações nos padrões migratórios secundários tendem a ocorrer de forma mais consistente entre regiões que apresentam disparidades de renda e emprego menos expressivas, como ocorre no centro-sul do país.

A diminuição da participação dos tradicionais destinos fluminenses em relação a localidades da região centro-sul ocorre em magnitudes mais significativas quando comparadas às trajetórias das regiões menos desenvolvidas do Brasil. O ritmo de expansão das trajetórias que envolvem estas regiões é mais lento e ocorre em pontos isolados do território nacional, pois a manutenção das redes de contado entre migrantes e não migrantes, no destino e na origem, tende a estimular o componente inercial do padrão migratório dominante entre estas regiões. Os dados censitários indicam que o desejo de migrar para o sudeste para prosperar economicamente persiste, especialmente no Nordeste.

Nessa perspectiva, pretende-se, a partir da análise dos microdados da PNAD para o período 2011-2015, observar como as alterações recentes nos contextos socioeconômicos de uma das principais regiões absorvedoras de migrantes do país, o estado do Rio de Janeiro, afetaram suas trajetórias migratórias. O objetivo é analisar se os impactos da crise econômico-financeira estadual, deflagrada a partir de 2014, estão associados a mudanças imediatas e expressivas sobre a capacidade de retenção e atração populacional (i.e.: evolução do saldo migratório) e o perfil do migrante. Supõe-se que os microdados da PNAD indicarão uma associação negativa entre a perda de competitividade e dinamismo local e a evolução das trajetórias migratórias fluminenses. Apesar disso, o caráter inercial dos fluxos migratórios dominantes no Brasil provavelmente contribuirá para a manutenção da importância relativa desse importante destino migratório nacional. 
Matrizes migratórias pós-2010: tendências recentes sobre a capacidade de atração populacional fluminense

Os fatores de atração e repulsão populacional, sintetizados pelos modelos Push-Pull, são utilizados para analisar a migração sob uma perspectiva espacial, identificando porque alguns indivíduos de determinadas regiões migram enquanto outros não, bem como porque os fluxos migratórios tendem a se estabelecer entre regiões de origem e destino específicas (DE HAAS, 2008). Neste framework, a migração é definida como uma escolha que envolve uma origem, um destino e um conjunto de obstáculos e intervenções. Cada localidade possui, simultaneamente, fatores que atraem indivíduos, chamados pull factors, e fatores que os repelem, chamados push factors. Alguns fatores afetam a maior parte dos indivíduos de forma homogênea, outros de forma heterogênea, ou seja, o conjunto de fatores positivos e negativos depende das percepções individuais e, portanto, é diferente para cada migrante potencial. Apesar destas limitações, é possível identificar grupos de indivíduos que reagem de forma similar a estes fatores.

No caso do Brasil, Da Mata et al. (2007) analisam, para o ano 2000, quais são as características das cidades que mais atraem migrantes qualificados e verificam que estes indivíduos tendem a se direcionar para localidades com maior dinamismo nos mercados de trabalho (salários mais elevados) e menores níveis de desigualdade social e violência. Justo e Silveira Neto (2008a) analisam a influência de variáveis de atratividade para a determinação da taxa líquida de migração estadual entre 1980 e 2000 e concluem que aproximadamente $40 \%$ da taxa líquida de migração estadual são explicados pela renda esperada de cada localidade. Lima et al. (2016) identificam, a partir da análise dos microdados dos Censos Demográficos de 1980 a 2010, que os deslocamentos populacionais recentes no Brasil guardam elevada relação com os respectivos níveis de desenvolvimento urbano-regional e estão associados às vantagens dos centros urbanos.

Dada a expressiva importância relativa da economia fluminense como região absorvedora de migrantes no país, ressaltada na seção 1, e sua conjuntura econômico-financeira desfavorável pós-2014, é interessante observar as tendências recentes de seus fluxos migratórios e o perfil de seus migrantes. A ideia subjacente é analisar se a crise e a estagnação econômicas estão associadas a mudanças imediatas sobre a capacidade de retenção e atração populacional e o perfil do migrante.

Para a consecução do objetivo proposto, serão utilizados os microdados da PNAD 2011-2015, fornecidos pelo Instituto Brasileiro de Geografia e Estatística (IBGE), para construir matrizes migratórias interestaduais (longa distância) que permitirão identificar as respectivas regiões de origem e destino dos migrantes, cujo critério de definição refere-se à naturalidade. A identificação do perfil desses migrantes será realizada na seção 03.

As Tabelas 2 e 3 demonstram a composição amostral por ano para o Brasil e para o estado do Rio de Janeiro. Observa-se que a migração interestadual (longa distância) possui importância relativa mais expressiva 
para o estado do Rio de Janeiro do que para a média nacional ( $23 \%$ versus $15 \%$, respectivamente). No período de 05 anos, houve relativa estabilidade do volume de migrantes em ambos os casos. Todavia, é importante ressaltar que no último ano da série há uma redução desses fluxos.

Tabela 2. Composição amostral (Brasil, 2011-2015). Fonte: elaboração própria a partir dos microdados da PNAD.

\begin{tabular}{|c|c|c|c|c|}
\hline & Amostra & (\%) & População & (\%) \\
\hline 2011 & 358.919 & 19,9 & 197.825 .297 & 19,6 \\
\hline 2012 & 362.451 & 20,1 & 199.688.907 & 19,8 \\
\hline 2013 & 362.554 & 20,1 & 201.466 .785 & 20,0 \\
\hline 2014 & 362.627 & 20,1 & 203.190 .852 & 20,2 \\
\hline 2015 & 356.904 & 19,8 & 204.860 .101 & 20,3 \\
\hline \multicolumn{5}{|c|}{ Migrantes Interestaduais } \\
\hline & Amostra & (\%) & População & (\%) \\
\hline 2011 & 56.610 & $15,8 \%$ & 31.173 .018 & $15,8 \%$ \\
\hline 2012 & 56.875 & $15,7 \%$ & 31.251 .179 & $15,6 \%$ \\
\hline 2013 & 56.600 & $15,6 \%$ & 31.292 .827 & $15,5 \%$ \\
\hline 2014 & 57.239 & $15,8 \%$ & 32.126 .299 & $15,8 \%$ \\
\hline 2015 & 54.373 & $15,2 \%$ & 31.426 .324 & $15,3 \%$ \\
\hline
\end{tabular}

Tabela 3. Composição amostral (Rio de Janeiro, 2011-2015). Fonte: elaboração própria a partir dos microdados da PNAD.

\begin{tabular}{|c|c|c|c|c|}
\hline & Amostra & (\%) & População & (\%) \\
\hline 2011 & 38.237 & 19,3 & 42.987 .339 & 19,7 \\
\hline 2012 & 39.099 & 19,8 & 43.387 .111 & 19,8 \\
\hline 2013 & 39.531 & 20,0 & 43.769.155 & 20,0 \\
\hline 2014 & 41.057 & 20,7 & 44.140 .082 & 20,2 \\
\hline 2015 & 40.008 & 20,2 & 44.499 .755 & 20,3 \\
\hline \multicolumn{5}{|c|}{ Migrantes Interestaduais } \\
\hline & Amostra & (\%) & População & (\%) \\
\hline 2011 & 8.961 & $23,4 \%$ & 9.964 .063 & $23,2 \%$ \\
\hline 2012 & 9.082 & $23,2 \%$ & 9.996 .856 & $23,0 \%$ \\
\hline 2013 & 9.118 & $23,1 \%$ & 10.009 .653 & $22,9 \%$ \\
\hline 2014 & 9.798 & $23,9 \%$ & 10.461 .396 & $23,7 \%$ \\
\hline 2015 & 9.183 & $23,0 \%$ & 10.141 .078 & $22,8 \%$ \\
\hline
\end{tabular}

Em relação à evolução das capacidades de atração e retenção populacional do estado no Rio de Janeiro no período 2011-2015, os dados da Tabela 04 indicam uma associação negativa com a perda de dinamismo e competitividade local. Entre 2011 e 2012, houve uma expansão de aproximadamente 10\% do saldo migratório fluminense, cujas principais regiões de origem estavam localizadas, respectivamente, nos estados de Minas Gerais (23,7\%), Paraíba (14,5\%), Ceará (10\%), Espírito Santo (8,9\%), Pernambuco (8,7\%), Bahia $(8,4 \%)$ e São Paulo (6,3\%). Essa expansão do saldo migratório, ou seja, a recuperação da capacidade de atração populacional está associada ao aumento dos investimentos produtivos no estado relacionados à indústria 
química e petroquímica (principalmente nas microrregiões de Macaé e Campos dos Goytacazes) e a investimentos em infraestrutura urbana vinculados à realização de eventos internacionais (Copa do Mundo e Olimpíadas).

Todavia, a partir de 2012, o saldo migratório fluminense apresenta taxas de variação negativas (-3,3\%, $-2,7 \%$ e $-4,6 \%)$ associadas à deflagração da crise econômico-financeira estadual. A magnitude da redução equivale à uma pequena retração da capacidade de atração populacional do estado no período como um todo $(-1,1 \%)$. Na realidade, observa-se uma estabilidade do saldo migratório estadual entre 2011 e 2015, o que evidencia o caráter inercial dessa trajetória migratória dominante no contexto nacional. Em outras palavras, apesar da redução da atratividade econômica estadual no período (diminuição dos fatores de atração populacional devido à crise econômica), o caráter inercial dos fluxos migratórios dominantes no Brasil (viabilizado por redes de contato, por exemplo), tem contribuído para a manutenção da importância relativa desse importante destino migratório nacional.

Tabela 4. Matriz migratória interestadual (Rio de Janeiro, 2011-2015). Fonte: elaboração própria a partir dos microdados da

\begin{tabular}{|c|c|c|c|c|c|c|}
\hline \multicolumn{7}{|c|}{$\begin{array}{r}\text { PNAD. } \\
\end{array}$} \\
\hline & & 2011 & 2012 & 2013 & 2014 & 2015 \\
\hline \multirow{27}{*}{ 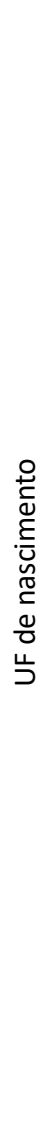 } & RO & 3.272 & 2.552 & 4.496 & 4.532 & 1.292 \\
\hline & $A C$ & 1.347 & 4.467 & 3.848 & 2.585 & 3.835 \\
\hline & AM & 17.804 & 12.581 & 11.542 & 15.564 & 13.385 \\
\hline & RR & 0 & 1.277 & 0 & 0 & 0 \\
\hline & PA & 70.348 & 44.908 & 52.932 & 42.772 & 36.326 \\
\hline & AP & 0 & 3.116 & 3.201 & 645 & 636 \\
\hline & TO & 1.252 & 638 & 1.870 & 5.170 & 3.857 \\
\hline & MA & 81.687 & 94.376 & 91.815 & 80.368 & 91.732 \\
\hline & PI & 22.415 & 37.958 & 31.576 & 52.484 & 37.576 \\
\hline & CE & 243.133 & 204.496 & 209.919 & 206.695 & 219.463 \\
\hline & RN & 57.445 & 90.856 & 70.599 & 71.922 & 68.859 \\
\hline & PB & 340.850 & 356.876 & 352.394 & 296.225 & 329.779 \\
\hline & PE & 207.168 & 215.725 & 196.138 & 221.617 & 177.152 \\
\hline & $\mathrm{AL}$ & 48.304 & 58.229 & 52.579 & 55.082 & 58.679 \\
\hline & SE & 40.600 & 45.613 & 37.044 & 45.385 & 45.331 \\
\hline & BA & 198.319 & 233.137 & 184.967 & 200.837 & 212.211 \\
\hline & MG & 563.975 & 570.021 & 562.280 & 564.714 & 569.528 \\
\hline & ES & 210.879 & 202.942 & 205.081 & 215.586 & 171.303 \\
\hline & RJ & - & - & - & - & - \\
\hline & SP & 150.306 & 135.903 & 163.658 & 176.683 & 156.963 \\
\hline & PR & 21.270 & 34.614 & 23.159 & 27.828 & 37.139 \\
\hline & SC & 11.645 & 18.998 & 14.674 & 11.660 & 15.970 \\
\hline & RS & 37.327 & 42.423 & 40.496 & 30.462 & 31.925 \\
\hline & MS & 9.816 & 9.572 & 10.289 & 10.349 & 8.284 \\
\hline & MT & 7.984 & 6.268 & 13.381 & 14.249 & 7.034 \\
\hline & GO & 6.353 & 8.708 & 8.920 & 14.239 & 8.940 \\
\hline & DF & 23.875 & 10.136 & 21.287 & 23.329 & 19.126 \\
\hline \multicolumn{2}{|c|}{ Imigrantes } & 2.377 .374 & 2.446 .390 & 2.368 .145 & 2.390 .982 & 2.326 .325 \\
\hline \multicolumn{2}{|c|}{ Emigrantes } & 1.019 .386 & 953.653 & 922.144 & 983.619 & 983.377 \\
\hline \multicolumn{2}{|c|}{ Saldo } & 1.357 .988 & 1.492 .737 & 1.446 .001 & 1.407 .363 & 1.342 .948 \\
\hline
\end{tabular}




\section{O perfil do imigrante fluminense}

A migração é o resultado de decisões individuais tomadas por agentes racionais que desejam aumentar seu bem-estar ao se deslocarem de um lugar para outro, no qual a recompensa - geralmente monetária - por seu trabalho é maior do que a obtida na localidade de origem em uma medida suficiente para compensar os custos tangíveis e intangíveis derivados do deslocamento. A migração é, portanto, um ato individual baseado na comparação entre a situação atual do agente e o ganho líquido esperado derivado do deslocamento. Uma vez analisadas todas as alternativas possíveis, os migrantes tendem a se deslocar para os locais nos quais esperam obter um rendimento líquido maior. Por envolver risco e incerteza, supõe-se que há seletividade no processo migratório, ou seja, os migrantes tendem a ser mais qualificados e empreendedores do que a média da população (SJAASTAD, 1962; TODARO, 1969; BORJAS, 1994; TAYLOR, 1999; BORJAS E KATZ, 2007).

Justo e Silveira Neto (2008b) realizam uma caracterização dos migrantes brasileiros de acordo com suas regiões de destino. Os autores estimam um modelo logit multinomial (não ordenado) para a decisão de migrar e a escolha da região de destino utilizando dados dos censos demográficos 1980 a 2000. Os resultados do modelo evidenciam que indivíduos do sexo masculino, brancos, mais jovens e escolarizados, casados e com filhos e chefes do domicílio possuem maior probabilidade de migrar. Além disso, se a UF de origem destes indivíduos é deprimida esta probabilidade aumenta. A análise dos autores é corroborada e estendida para o período 1980-2010 por Lima et al. (2016): os migrantes internos no Brasil são positivamente selecionados. Inclusive, utilizam o deslocamento como uma estratégia para minimização do risco de renda (LIMA et al., 2015).

Nessa perspectiva e considerando a relativa estabilidade do papel de "região absorvedora de mão de obra" do estado do Rio de Janeiro, pretende-se identificar se as alterações recentes em sua conjuntura econômico-financeira (crise e estagnação) estão associadas a mudanças no perfil de seus migrantes. A base de dados utilizada, construída a partir dos microdados da PNAD 2011-2015, possui informações sobre as características produtivas (educação, trabalho, rendimento etc.) e não produtivas (sexo, cor, estrutura familiar, condição domiciliar etc.) dos migrantes, o que permite identificar se os migrantes compõem (ou não) um grupo homogêneo e positivamente selecionado.

É importante ressaltar que alguns recortes foram realizados para tornar a amostra mais homogênea: indivíduos que se declararam indígenas ou amarelos foram excluídos da amostra, assim como domicílios improvisados, coletivos ou sem chefe. Os rendimentos foram atualizados para valores de 2018 a partir do Índice Nacional de Preços ao Consumidor Amplo (IPCA). As variáveis indicadoras dos setores de atividade da 
população economicamente ativa foram agregadas em 12 categorias. ${ }^{3}$ Analogamente, foram criadas 09 categorias ocupacionais. ${ }^{4}$ A partir dos quesitos educacionais foram criadas variáveis para indicar a quantidade de anos de estudo dos indivíduos, classificando-os em 05 grupos de escolaridade. ${ }^{5}$

A Tabela 5 apresenta informações sobre as características não produtivas dos imigrantes fluminenses:

Tabela 5. Migrantes - Características não produtivas (Rio de Janeiro, 2011-2015). Fonte: elaboração própria a partir dos microdados da PNAD.

\begin{tabular}{lccccc}
\hline & $\mathbf{2 0 1 1}$ & $\mathbf{2 0 1 2}$ & $\mathbf{2 0 1 3}$ & $\mathbf{2 0 1 4}$ & $\mathbf{2 0 1 5}$ \\
\hline Homens & $47,6 \%$ & $47,2 \%$ & $47,3 \%$ & $47,3 \%$ & $46,0 \%$ \\
Mulheres & $52,4 \%$ & $52,8 \%$ & $52,7 \%$ & $52,7 \%$ & $54,0 \%$ \\
Brancos & $51,9 \%$ & $50,6 \%$ & $50,9 \%$ & $48,3 \%$ & $48,1 \%$ \\
Pretos e pardos & $48,1 \%$ & $49,4 \%$ & $49,1 \%$ & $51,7 \%$ & $51,9 \%$ \\
Resp. Dom. & $48,8 \%$ & $48,9 \%$ & $49,9 \%$ & $49,5 \%$ & $50,4 \%$ \\
União estável & $67,4 \%$ & $66,0 \%$ & $66,6 \%$ & $67,5 \%$ & $66,4 \%$ \\
Casal com dependentes & $27,1 \%$ & $26,0 \%$ & $25,5 \%$ & $23,4 \%$ & $21,8 \%$ \\
\hline
\end{tabular}

Observa-se que as mulheres constituem a maior parcela dos migrantes (54\% em 2015), um provável reflexo das tendências demográficas recentes. Em 2011, aproximadamente 52\% da amostra era composta por indivíduos que se autodeclaravam brancos e 48\% pretos e pardos; em 2015, houve uma alteração destas proporções (48\% e 52\%, respectivamente). Esta mudança pode estar associada a ajustes realizados pelo IBGE para minimizar os problemas de coleta deste quesito e aos estímulos socioculturais que existem para os indivíduos se declararem pretos ou pardos mais recentemente.

No período analisado, entre 48\% e 52\% dos migrantes são responsáveis pelos domicílios (deslocamento como uma estratégia para minimizar o risco de renda domiciliar). Desde montante, em 2015, aproximadamente 58,5\%\% são homens (manutenção da posição predominantemente masculina como "chefe do domicílio"). A despeito dessa manutenção, houve no período redução da participação masculina em prol das mulheres, cujo percentual subiu de 37\% em 2011 para 41,5\% em 2015. A evolução destas proporções reflete a emancipação feminina e as transformações ocorridas nas estruturas familiares brasileiras nas últimas décadas do século XX. Ressalta-se que a maior parte da amostra é composta por indivíduos que declaram ter

\footnotetext{
3 Atividades agrícolas, indústria de transformação, outras indústrias, construção, comércio e serviços de reparação, alojamento e alimentação, transportes, administração pública, serviços educacionais, de saúde e pessoais, serviços domésticos, outros serviços e outras atividades.

${ }^{4}$ Dirigentes, profissionais das ciências e das artes, técnicos de nível médio, técnicos administrativos, trabalhadores dos serviços, vendedores e prestadores de serviços, trabalhadores agrícolas, trabalhadores da produção de bens e serviços e forças armadas.

${ }^{5} 0$ a 3 anos de estudo, 4 a 7 anos de estudo, 8 a 10 anos de estudo, 11 a 14 anos de estudo e 15 ou mais anos de estudo.
} 
união conjugal estável (aproximadamente 66\%), contudo, menos de 25\% dos migrantes (em média) pertencem a estruturas familiares compostas por casal com filhos dependentes (menores de 15 anos).

As características educacionais dos migrantes residentes no estado do Rio de Janeiro são analisadas por intermédio da variável "anos de estudo", sintetizada em grupos educacionais (consultar Tabela 06 e Gráfico 01 a seguir). A proporção de migrantes alfabetizados manteve-se estável no período (92\%). Os percentuais de alfabetização são basicamente os mesmos para migrantes e não migrantes. Pequena parcela dos migrantes frequenta a escola, o que corrobora a hipótese de que o deslocamento tende a se efetivar após a conclusão do ciclo educacional dos indivíduos (migração ocorre majoritariamente para inserção no mercado de trabalho). As informações por grupos de escolaridade e média de anos de estudo evidenciam os progressos educacionais dos migrantes (Tabela 6), bem como possibilitam uma comparação com os não migrantes (Figura 1):

Tabela 6. Migrantes - Características educacionais (Rio de Janeiro, 2011-2015). Fonte: elaboração própria a partir dos microdados da

\begin{tabular}{lccccc}
\hline \multicolumn{7}{c}{ PNAD. } \\
\hline Analfabetos & $\mathbf{2 0 1 1}$ & $\mathbf{2 0 1 2}$ & $\mathbf{2 0 1 3}$ & $\mathbf{2 0 1 4}$ & $\mathbf{2 0 1 5}$ \\
Alfabetizados & $8,0 \%$ & $8,4 \%$ & $8,6 \%$ & $8,4 \%$ & $7,9 \%$ \\
Freq. Escola & $92,0 \%$ & $91,6 \%$ & $91,4 \%$ & $91,6 \%$ & $92,1 \%$ \\
0 a 3 anos de estudo & $8,3 \%$ & $8,0 \%$ & $7,9 \%$ & $7,9 \%$ & $7,2 \%$ \\
4 a 7 anos de estudo & $23,5 \%$ & $22,2 \%$ & $22,1 \%$ & $21,6 \%$ & $20,8 \%$ \\
8 a 10 anos de estudo & $24,7 \%$ & $25,0 \%$ & $24,5 \%$ & $25,3 \%$ & $24,3 \%$ \\
11 a 14 anos de estudo & $18,3 \%$ & $17,4 \%$ & $18,5 \%$ & $17,1 \%$ & $17,8 \%$ \\
15 ou mais anos de estudo & $26,8 \%$ & $28,6 \%$ & $27,5 \%$ & $28,2 \%$ & $29,1 \%$ \\
\hline
\end{tabular}

A Tabela 6 demonstra que houve uma redução contínua da proporção de migrantes com baixos níveis de escolaridade. A proporção de migrantes com 0 a 3 anos de estudo caiu de 23,5\% em 2011 para 20,8\% em 2015, a proporção de migrantes com 4 a 7 anos de estudo manteve-se estável e houve redução do grupo de 8 a 10 anos de estudo. As participações relativas dos grupos de educação intermediária (11 a 14 anos de estudo) e elevada (15 anos ou mais) aumentaram no período. Esta última categoria continua pouco expressiva, mas há uma aparente tendência de crescimento. Estes dados, quando analisados em conjunto com a média de anos de estudo (Gráfico 01) indicam que estes progressos foram mais expressivos para os migrantes. Em outras palavras, os quesitos educacionais demonstram a seletividade da migração: os migrantes possuem média de anos de estudo superior à dos não migrantes. 
Figura 1. Evolução da Média de anos de estudo (Rio de Janeiro, 2011-2015). Fonte: elaboração própria a partir dos microdados da PNAD.

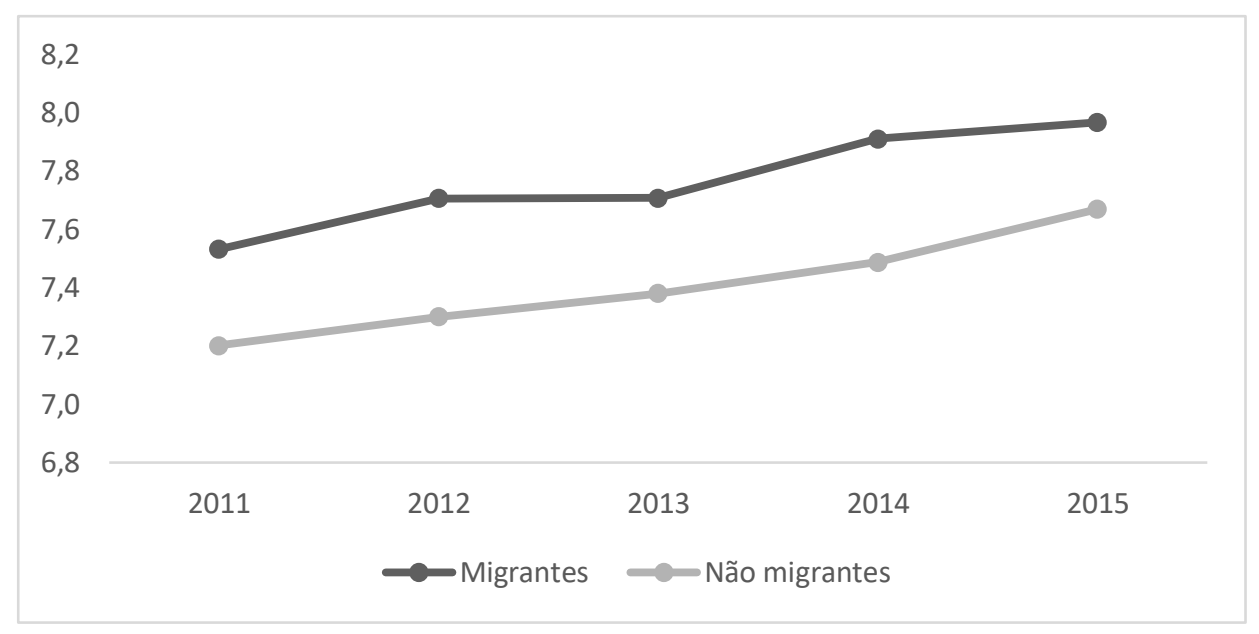

Como citado anteriormente, um dos principais determinantes da migração é o desejo de prosperar economicamente. Logo, é importante observar as características ocupacionais da amostra. A Tabela 7 a seguir mostra a proporção de migrantes por condição de atividade e ocupação. O percentual de ocupados diminuiu de 61,2\% em 2011 para 58,7\% em 2015, um provável reflexo do baixo dinamismo dos mercados de trabalho fluminenses a partir de 2014. Simultaneamente, ocorreu uma redução de 1 p.p. da proporção de migrantes pertencentes à população economicamente inativa (somatório de ocupados e desocupados) e aumentou o percentual de migrantes desocupados (de 3,6\% para 5,1\%), assim como sua taxa de desocupação (de 5,6\% para 8,0\%). Estes movimentos podem estar associados à elevação da dificuldade de inserção ocupacional em um contexto de redução da oferta de vagas de trabalho (crise econômica) e/ou à incompatibilidade entre a qualificação da mão de obra e os requisitos solicitados pelo mercado de trabalho. A distribuição dos postos de trabalho por sexo era mais desequilibrada em 2011 (58,5\% dos migrantes ocupados eram homens e 41,5\%, mulheres). Essa diferença diminuiu no decorrer do período: apesar dos homens ainda representarem a maior parcela da força de trabalho migrante $(55,8 \%)$, as mulheres conseguiram aumentar sua inserção ocupacional (44,2\%). Ressalta-se que a proporção de desocupados e as taxas de desocupação são mais expressivas para os não migrantes (6\% e 10\%, respectivamente, em 2015), o que reflete o provável caráter seletivo do processo migratório (migrantes são mais qualificados, em média, logo, são um pouco menos afetados por conjunturas econômicas desfavoráveis).

Tabela 7. Migrantes - Condição de atividade e ocupação (Rio de Janeiro, 2011-2015). Fonte: elaboração própria a partir dos microdados da PNAD.

\begin{tabular}{l|c|c|c|c|c}
\hline & $\mathbf{2 0 1 1}$ & $\mathbf{2 0 1 2}$ & $\mathbf{2 0 1 3}$ & $\mathbf{2 0 1 4}$ & $\mathbf{2 0 1 5}$ \\
\hline Inativos & $35,2 \%$ & $35,8 \%$ & $36,0 \%$ & $36,5 \%$ & $36,2 \%$ \\
\hline
\end{tabular}




\begin{tabular}{l|c|c|c|c|c} 
desocupados & $3,6 \%$ & $3,1 \%$ & $3,3 \%$ & $3,7 \%$ & $5,1 \%$ \\
\hline ocupados & $61,2 \%$ & $61,1 \%$ & $60,6 \%$ & $59,8 \%$ & $58,7 \%$ \\
\hline Taxa de desocupação & $5,6 \%$ & $4,8 \%$ & $5,2 \%$ & $5,9 \%$ & $8,0 \%$ \\
\hline Taxa de ocupação & $94,4 \%$ & $95,2 \%$ & $94,8 \%$ & $94,1 \%$ & $92,0 \%$ \\
\hline
\end{tabular}

Em relação à posição de ocupação dos migrantes (no trabalho principal), observa-se (Tabela 8) a seguinte ordem de importância (sem alterações significativas no período analisado): empregados com CTPS, trabalhadores por conta-própria e empregados sem CTPS. A proporção de migrantes em atividades informais (sem CTPS, sem remuneração e para consumo ou construção próprios) diminuiu aproximadamente 2 p.p. entre 2011 e 2015.

Tabela 8. Migrantes - Posição na ocupação (Rio de Janeiro, 2011-2015). Fonte: elaboração própria a partir dos microdados da PNAD.

\begin{tabular}{lccccc}
\hline & $\mathbf{2 0 1 1}$ & $\mathbf{2 0 1 2}$ & $\mathbf{2 0 1 3}$ & $\mathbf{2 0 1 4}$ & $\mathbf{2 0 1 5}$ \\
\hline Empregado com CTPS & $50,2 \%$ & $51,6 \%$ & $50,0 \%$ & $50,0 \%$ & $50,5 \%$ \\
Militar & $0,1 \%$ & $0,3 \%$ & $0,4 \%$ & $0,3 \%$ & $0,5 \%$ \\
Func. Pub. & $3,6 \%$ & $3,4 \%$ & $3,4 \%$ & $3,7 \%$ & $3,7 \%$ \\
Sem CTPS & $10,1 \%$ & $10,3 \%$ & $9,6 \%$ & $9,5 \%$ & $8,8 \%$ \\
Domest. com CTPS & $5,0 \%$ & $5,0 \%$ & $5,6 \%$ & $5,3 \%$ & $5,0 \%$ \\
Domest. sem CTPS & $6,7 \%$ & $6,2 \%$ & $6,0 \%$ & $6,2 \%$ & $6,4 \%$ \\
Conta própria & $20,2 \%$ & $18,5 \%$ & $20,3 \%$ & $20,0 \%$ & $21,0 \%$ \\
Empregador & $2,8 \%$ & $3,8 \%$ & $3,8 \%$ & $3,8 \%$ & $3,0 \%$ \\
Consumo próprio & $0,4 \%$ & $0,3 \%$ & $0,3 \%$ & $0,3 \%$ & $0,4 \%$ \\
Construção própria & $0,2 \%$ & $0,0 \%$ & $0,1 \%$ & $0,2 \%$ & $0,2 \%$ \\
Sem remuneração & $0,7 \%$ & $0,6 \%$ & $0,5 \%$ & $0,7 \%$ & $0,6 \%$ \\
\hline
\end{tabular}

Os trabalhadores migrantes concentram-se principalmente nos setores de serviços (subdivididos em alojamento e alimentação, educação, saúde, serviços pessoais e transportes e serviços domésticos), indústria de transformação, comércio e reparação e construção civil. A evolução desta distribuição pode ser visualizada na Tabela 09, cuja tendência mais expressiva é a diminuição relativa do emprego na indústria de transformação. Esse setor foi um dos principais atingidos pela crise econômico-financeira estadual (redução dos investimentos setoriais, do valor bruto da produção e aumento da capacidade ociosa).

Tabela 9. Migrantes - Setor de atividade* (Rio de Janeiro, 2011-2015). Fonte: elaboração própria a partir dos microdados da PNAD.

\begin{tabular}{lccccc}
\hline & $\mathbf{2 0 1 1}$ & $\mathbf{2 0 1 2}$ & $\mathbf{2 0 1 3}$ & $\mathbf{2 0 1 4}$ & $\mathbf{2 0 1 5}$ \\
\hline Agrícola & $3,3 \%$ & $3,1 \%$ & $3,5 \%$ & $3,1 \%$ & $3,3 \%$ \\
Ind. Outras & $0,3 \%$ & $0,3 \%$ & $0,3 \%$ & $0,3 \%$ & $0,3 \%$ \\
Ind. Transformação & $18,7 \%$ & $19,0 \%$ & $17,1 \%$ & $17,0 \%$ & $16,4 \%$ \\
\hline
\end{tabular}




\begin{tabular}{lccccc}
\hline Construção & $11,9 \%$ & $12,4 \%$ & $13,3 \%$ & $13,4 \%$ & $12,3 \%$ \\
Comércio e rep. & $16,1 \%$ & $16,5 \%$ & $16,8 \%$ & $17,9 \%$ & $16,9 \%$ \\
Alojam. e Alim. & $7,7 \%$ & $7,9 \%$ & $6,9 \%$ & $6,4 \%$ & $7,4 \%$ \\
Transportes & $6,2 \%$ & $6,8 \%$ & $7,0 \%$ & $6,1 \%$ & $6,1 \%$ \\
Adm. Pub. & $2,5 \%$ & $2,6 \%$ & $2,7 \%$ & $2,4 \%$ & $2,8 \%$ \\
Educ. Saúde e serv. Pessoais & $6,3 \%$ & $6,4 \%$ & $6,8 \%$ & $7,3 \%$ & $7,6 \%$ \\
Serv. Domésticos & $11,7 \%$ & $11,2 \%$ & $11,6 \%$ & $11,5 \%$ & $11,3 \%$ \\
Outros serviços & $4,6 \%$ & $4,0 \%$ & $4,5 \%$ & $4,3 \%$ & $4,6 \%$ \\
Outras Atividades & $10,5 \%$ & $9,9 \%$ & $9,5 \%$ & $10,3 \%$ & $10,8 \%$ \\
\hline
\end{tabular}

$(*)$ Exclui atividades mal definidas

A maior parte dos trabalhadores migrantes desempenha funções de baixa qualificação (trabalhadores dos serviços e trabalhadores na produção de bens e serviços) (Tabela 10). Não há diferenças significativas em relação aos não migrantes. Esses dados refletem características dos mercados de trabalhos locais relacionadas à: (i) especialização produtiva em atividades pouco intensivas em capital e inovação (comparação internacional); (ii) baixa necessidade de utilização de capital humano (escassez de demanda por capital humano, ou seja, oferta de vagas para postos de trabalho qualificados geralmente é limitada); e (iii) escolaridade média da população é baixa, assim como seu nível de qualificação profissional (escassez de oferta de capital humano).

Tabela 10. Migrantes - Categorias ocupacionais* (Rio de Janeiro, 2011-2015). Fonte: elaboração própria a partir dos microdados da PNAD.

\begin{tabular}{l|c|c|c|c|c}
\hline & $\mathbf{2 0 1 1}$ & $\mathbf{2 0 1 2}$ & $\mathbf{2 0 1 3}$ & $\mathbf{2 0 1 4}$ & $\mathbf{2 0 1 5}$ \\
\hline Dirigentes & $4,0 \%$ & $5,1 \%$ & $4,9 \%$ & $5,1 \%$ & $4,9 \%$ \\
\hline Prof. Ciências e Artes & $5,8 \%$ & $6,0 \%$ & $6,4 \%$ & $6,9 \%$ & $6,8 \%$ \\
\hline Tec. Médio & $6,1 \%$ & $5,0 \%$ & $5,6 \%$ & $5,6 \%$ & $6,1 \%$ \\
\hline Tec. Serv. Adm. & $6,9 \%$ & $8,2 \%$ & $7,4 \%$ & $7,1 \%$ & $7,3 \%$ \\
\hline Trab. Serv. & $30,2 \%$ & $29,7 \%$ & $29,0 \%$ & $29,6 \%$ & $31,4 \%$ \\
\hline $\begin{array}{l}\text { Vendedores e prestadores de } \\
\text { serviços }\end{array}$ & $9,3 \%$ & $8,9 \%$ & $9,4 \%$ & $9,2 \%$ & $9,1 \%$ \\
\hline Trab. Agrícolas & $3,1 \%$ & $2,9 \%$ & $3,4 \%$ & $2,9 \%$ & $3,2 \%$ \\
\hline Trab. Produção de B\&S & $34,2 \%$ & $33,6 \%$ & $33,3 \%$ & $32,9 \%$ & $30,4 \%$ \\
\hline Forças Armadas & $0,4 \%$ & $0,5 \%$ & $0,5 \%$ & $0,5 \%$ & $0,7 \%$ \\
\hline
\end{tabular}

$\left({ }^{*}\right)$ Exclui atividades mal definidas

As diferenças existentes entre os componentes amostrais refletem-se em seus respectivos rendimentos (do trabalho e domiciliar per capita). Entre 2011 e 2015, houve uma redução generalizada do rendimento do trabalho e do rendimento domiciliar per capita no estado do Rio de Janeiro, consequência de seu baixo crescimento econômico (Figuras 2 e 3). Embora generalizada, a redução dos rendimentos não ocorreu na mesma magnitude entre indivíduos: há diferenças significativas entre migrantes, não migrantes e indivíduos qualificados e de baixa qualificação: 
Figura 2. Rendimento do trabalho principal (Rio de Janeiro, 2011-2015). Fonte: elaboração própria a partir dos microdados da PNAD.

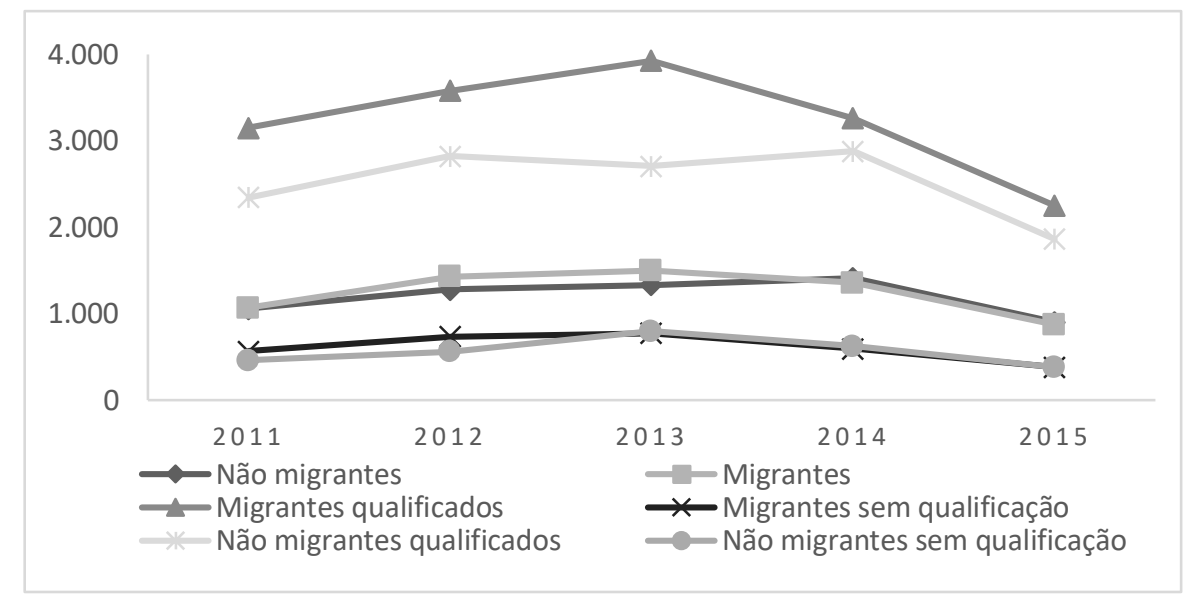

$(*)$ valores deflacionados pelo IPCA 2018.

$\left.{ }^{* *}\right)$ Qualificação $=15$ anos ou mais de estudo.

$(* * *)$ Não qualificação $=0$ a 3 anos de estudo.

Figura 3. Rendimento domiciliar per capita (Rio de Janeiro, 2011-2015). Fonte: elaboração própria a partir dos microdados da PNAD.

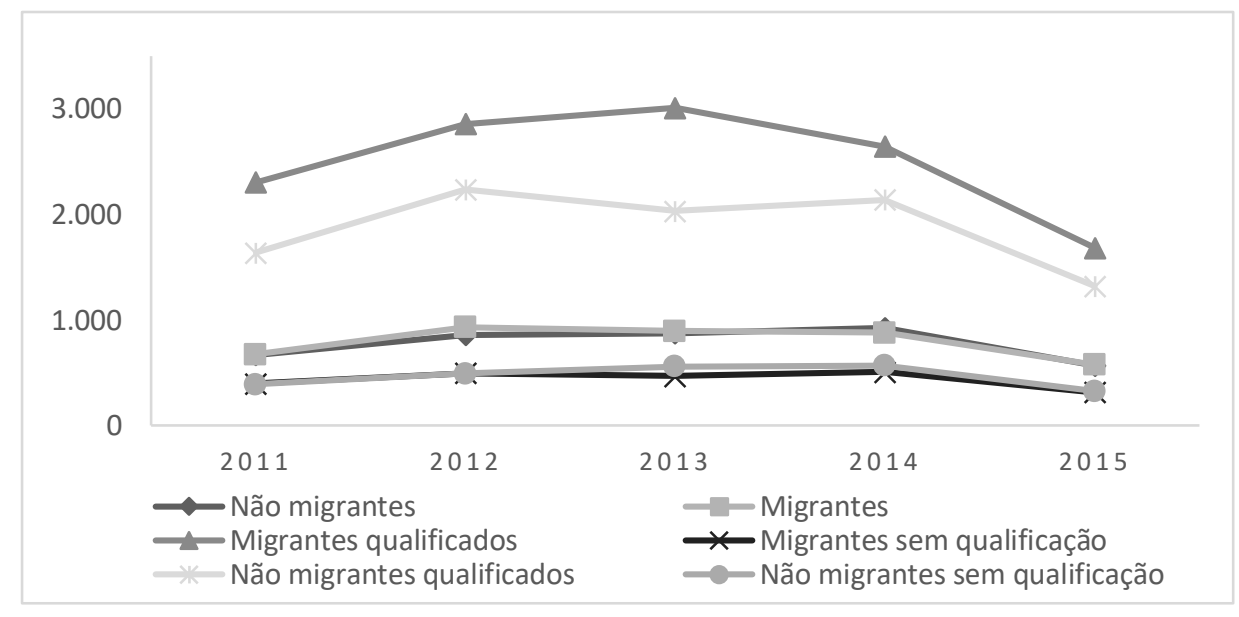

$\left({ }^{*}\right)$ valores deflacionados pelo IPCA 2018.

$(* *)$ Qualificação = 15 anos ou mais de estudo.

$(* * *)$ Não qualificação $=0$ a 3 anos de estudo.

O figura 2 acima mostra a evolução média do rendimento do trabalho principal de migrantes e não migrantes. Observa-se uma diferenciação entre os grupos, que tende a beneficiar os migrantes, especialmente os migrantes qualificados (15 anos ou mais de estudo). As médias dos migrantes ficaram acima da média estadual. O mesmo comportamento é observado em relação ao rendimento domiciliar per capita. Estes dados indicam que provavelmente a migração de longa distância é compensada por rendimentos mais elevados. Observa-se que qualificação individual e migração são importantes fatores de diferenciação salarial: indivíduos com maiores níveis de escolaridade possuem rendimentos significativamente mais elevados e a migração interestadual, confere benefícios monetários ainda mais expressivos. Em 2015, o rendimento médio de um 
migrante com 15 anos ou mais de estudo era aproximadamente 5,9 vezes maior do que o rendimento de um migrante sem qualificação (0 a 3 anos de estudo). Essas observações corroboram a hipótese de seleção positiva no processo migratório.

Essa diferenciação de rendimentos também pode ser observada sob outros aspectos. Por exemplo, as características não produtivas que estão positivamente relacionadas aos rendimentos são cor branca e sexo masculino, ou seja, os diferenciais de renda entre brancos e pretos (e pardos) e entre homens e mulheres persistem (segmentação dos mercados de trabalho).

Em resumo, a análise do perfil do imigrante fluminense indica a manutenção da seletividade do processo migratório: os homens, brancos, jovens, com situação conjugal estável e com elevados níveis de escolaridade possuem maior probabilidade de migrar. Há indícios de aumento da probabilidade de migrar das mulheres e de indivíduos pretos e pardos, conforme ressaltam Lima et al. (2016), todavia, estas características ainda não são as mais beneficiadas pelo processo migratório. Provavelmente, alterações mais expressivas no perfil dos migrantes exigem horizonte temporal mais amplo (médio e longo prazos).

\section{CONSIDERAÇÕES FINAIS}

O desenvolvimento socioeconômico de uma localidade está intrinsecamente relacionado à dinâmica dos deslocamentos de sua população (DE HAAS, 2008). A análise da trajetória de crescimento local requer o estudo das causas e dos impactos de cada um destes processos, caso contrário, sua interpretação pode ser limitada. Neste contexto, a migração deve ser compreendida como um processo integrante do desenvolvimento econômico, possuidor de dinâmica interna própria e que possui impactos específicos sobre as estruturas das localidades de origem e destino dos migrantes.

No caso do Rio de Janeiro, o padrão de desenvolvimento econômico afetou significativamente a dinâmica de seus fluxos migratórios e estes, por sua vez, condicionaram a trajetória do crescimento local. 0 caráter inercial das trajetórias migratórias dominantes no Brasil evidencia a manutenção da importância relativa da economia fluminense como região absorvedora de migrantes, a despeito da redução de seu saldo migratório no período 2011-2015.

A perda populacional do estado é explicada principalmente pela redução do saldo migratório da Região Metropolitana do Rio de Janeiro, pois seus elevados custos de congestionamento urbano (renda da terra, tempo de deslocamento casa-trabalho-estudo, violência, etc.) funcionam como fatores de repulsão populacional. Em contrapartida, localidades polarizadas por cidades médias, como, por exemplo, Campos dos Goytacazes e Macaé, ganharam importância no contexto macrorregional e tornaram-se áreas de absorção migratória. 
As tendências microrregionais evidenciam um processo de transição migratória, cuja trajetória foi interrompida pela crise econômico-financeira estadual iniciada em 2014. Em outras palavras, as transformações socioeconômicas desfavoráveis verificadas a partir desse ano reduziram as capacidades de atração e retenção populacional do Rio de Janeiro. Seus impactos só não foram mais expressivos devido à existência de redes de contato entre as regiões de origem e de destino dos migrantes fluminenses que contribuem continuadamente para a manutenção dos fluxos migratórios dominantes no cenário nacional, a saber: das regiões menos dinâmicas (norte e nordeste) para a região mais dinâmica (centro-sul, especialmente São Paulo e Rio de Janeiro).

A análise dos microdados da PNAD corrobora a hipótese de seletividade do processo migratório: homens, brancos, com situação conjugal estável e com elevados níveis de escolaridade compõem a maior parcela dos imigrantes fluminenses. Houve expansão dos indicadores para mulheres e indivíduos pretos e pardos, todavia, é pouco provável que mudanças estruturais ocorram em um período relativamente curto.

\section{REFERÊNCIAS}

BAENINGER, Rosana. Rotatividade migratória: um novo olhar para as migrações no século XXI. In: XVI ENCONTRO NACIONAL DE ESTUDOS POPULACIONAIS, Caxambu. Anais... Belo Horizonte: ABEP, 2008.

BARROS, R. P. CARVALHO, M.; FRANCO, S.; MENDONÇA, R. (2010). Determinantes da queda na desigualdade de renda no Brasil. IPEA Texto para Discussão № 1460.

BORJAS, George J. The economics of immigration. Journal of Economic Literature, v. 32, n. 4, p. 1667-1717, december, 1994.

BORJAS, George J.; KATZ, Lawrence F. The evolution of the Mexican-born workforce in the United States. In: BORJAS, George J. (ed). Mexican immigration to the United States. Cambridge M.A: National Bureau of Economic Research Conference Report, 2007.

BRITO, Fausto. População, espaço e economia: uma perspectiva histórica. 1997. 100fls. Tese (Doutorado em Demografia) - Centro de Desenvolvimento e Planejamento Regional, Universidade Federal de Minas Gerais, Belo Horizonte, 1997.

BRITO, Fausto. Brasil, final de século: a transição para um novo padrão migratório? In: CARLEIAL, Adelita Neto (org). Transições migratórias. Fortaleza: Edições IPLANCE, 2002.

BRITO, Fausto. O deslocamento da população brasileira para as metrópoles. Estudos Avançados, v. 57, p. 221-236, 2006.

BRITO, Fausto; CARVALHO, José Alberto Magno de. As migrações internas no Brasil e as novidades sugeridas pelos censos demográficos de 1991 e 2000 e pelas PNADS recentes. Parcerias estratégicas (Brasília), v. 22, p. 441-455, 2006.

DA MATA, Daniel, et al. Quais as características das cidades determinam a atração de migrantes qualificados? Brasília: IPEA, 2007. 20p. (Texto para discussão, 1305).

DE HAAS, Hein. The internal dynamics of migration process. In: IMSCOE Conference on Theories of Migration and Social Change. University of Oxford, 2008.

DE HAAS, Hein. Migration transitions: a theoretical and empirical inquiry into the developmental drivers of international migration. Oxford: IMI, 2010. 49p. (Working Papers, 24).

GIAMBIAGI, Fabio; PINHEIRO, Armando Castelar. Além da euforia: riscos e lacunas do modelo brasileiro de desenvolvimento. Rio de Janeiro: Elsevier, 2012.

INSTITUTO BRASILEIRO DE GEOGRAFIA E ESTATÍSTICA. Regiões de influência das cidades - REGIC. Rio de Janeiro: IBGE, 2008. INSTITUTO DE PESQUISA ECONÔMICA APLICADA. Perspectivas do desenvolvimento brasileiro - Livro 10. Brasília: IPEA, $2010 \mathrm{~b}$.

JUSTO, Wellington Ribeiro; SILVEIRA NETO, Raul da Mota. O que determina a migração interestadual no Brasil? Um modelo espacial para o período 1980-2000. Revista Econômica do Nordeste, v.39, n. 4, Fortaleza, out-dez, 2008 a. 
JUSTO, Wellington Ribeiro; SILVEIRA NETO, Raul da Mota. Quem são e para onde vão os migrantes no Brasil? O perfil do migrante interno brasileiro. In: XXXVI ENCONTRO NACIONAL DE ECONOMIA. Anais... Salvador, 2008b.

LIMA, Ana Carolina da Cruz; SIMÕES, R.; HERMETO, Ana Maria. Privação relativa e os deslocamentos da mão de obra no Brasil entre 1980 e 2010: evolução das interações entre pobreza, desigualdade de renda e migração. Pesquisa e Planejamento Econômico (Rio de Janeiro), v. 45, p. 7-36, 2015.

LIMA, Ana Carolina da Cruz; SIMÕES, R.; HERMETO, Ana Maria. Desenvolvimento regional, hierarquia urbana e condição de migração individual no Brasil entre 1980 e 2010. EURE (Santiago. Impresa), v. 42, p. 29-54, 2016.

SJAASTAD, Larry A. The costs and returns of human migration. The Journal of Political Economy, v. 70, n. 5, Part 2: Investment in human beings, p. 80-93, oct. 1962.

TAYLOR, J. Edward. The new economics of labour migration and the role of remittances in the migration process. International Migration, v. 37 (1), 1999.

TODARO, Michael P. A model of labor migration and urban unemployment in the less developed countries. American Economic Review, v. 59, n. 1, p. 136-148, March 1969.

WERNECK, Rogério Ladeira Furquim. Consolidação da estabilização e reconstrução institucional. In ABREU, Marcelo de Paiva (org.). A ordem do progresso: dois séculos de política econômica no Brasil. 2a Ed. Rio de Janeiro: Elsevier, 2014. 
APÊNDICE

Lima

Tabela A1. Matriz migratória interestadual por estado (Brasil, 2010). Fonte: elaboração própria a partir dos microdados do Censo Demográfico 2010.

\begin{tabular}{|c|c|c|c|c|c|c|c|c|c|c|c|c|c|c|c|c|c|c|c|c|c|c|c|c|c|c|c|c|}
\hline & & RO & $A C$ & AM & $\mathrm{RR}$ & PA & AP & TO & MA & $\mathrm{PI}$ & CE & $\mathrm{RN}$ & PB & $P E$ & AL & SE & BA & MG & ES & RJ & SP & $P R$ & SC & RS & MS & MT & GO & DF \\
\hline \multirow{27}{*}{ 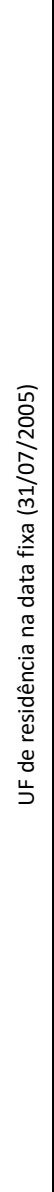 } & RO & - & 1.433 & 2.615 & 325 & 580 & 7 & 161 & 220 & 122 & 404 & 139 & 169 & 206 & 116 & 106 & 499 & 901 & 1.053 & 413 & 1.680 & 2.186 & 562 & 387 & 947 & 5.506 & 1.026 & 505 \\
\hline & $A C$ & 1.881 & & 1.246 & 77 & 160 & 2 & 56 & 26 & 0 & 81 & 41 & 4 & 53 & 81 & 18 & 61 & 179 & 0 & 197 & 260 & 147 & 107 & 112 & 138 & 311 & 380 & 201 \\
\hline & AM & 2.201 & 1.276 & - & 1.885 & 3.853 & 163 & 115 & 940 & 208 & 837 & 381 & 242 & 688 & 172 & 21 & 338 & 590 & 120 & 2.026 & 1.699 & 461 & 318 & 701 & 273 & 312 & 655 & 854 \\
\hline & RR & 243 & 26 & 1.340 & - & 429 & 6 & 31 & 567 & 52 & 330 & 122 & 132 & 122 & 28 & 0 & 44 & 192 & 32 & 194 & 316 & 86 & 92 & 278 & 113 & 66 & 124 & 206 \\
\hline & PA & 1.289 & 236 & 8.619 & 2.291 & - & 9.034 & 5.739 & 11.007 & 1.222 & 2.519 & 473 & 355 & 1.113 & 273 & 244 & 1.901 & 1.978 & 657 & 3.286 & 4.531 & 1.445 & 1.170 & 730 & 563 & 3.340 & 7.216 & 1.697 \\
\hline & AP & 36 & 0 & 332 & 22 & 3.243 & & 56 & 521 & 72 & 275 & 139 & 111 & 84 & 0 & 4 & 20 & 180 & 6 & 96 & 317 & 81 & 60 & 111 & 30 & 67 & 55 & 122 \\
\hline & TO & 504 & 20 & 109 & 106 & 6.106 & 42 & - & 2.742 & 392 & 303 & 38 & 98 & 337 & 83 & 31 & 548 & 1.348 & 92 & 283 & 1.296 & 471 & 161 & 142 & 263 & 844 & 10.636 & 1.534 \\
\hline & MA & 948 & 82 & 1.232 & 1.528 & 20.988 & 1.156 & 5.587 & - & 5.260 & 1.707 & 300 & 448 & 713 & 118 & 55 & 812 & 2.893 & 411 & 2.871 & 11.424 & 617 & 576 & 278 & 334 & 3.902 & 11.856 & 5.144 \\
\hline & PI & 214 & 49 & 418 & 170 & 1.659 & 119 & 862 & 6.877 & & 2.571 & 373 & 250 & 1.605 & 114 & 78 & 1.366 & 1.364 & 209 & 1.443 & 15.814 & 333 & 206 & 268 & 317 & 734 & 4.642 & 5.610 \\
\hline & CE & 550 & 256 & 1.316 & 359 & 2.350 & 254 & 472 & 1.738 & 2.980 & - & 3.310 & 1.699 & 4.194 & 668 & 327 & 3.148 & 2.775 & 318 & 7.578 & 18.808 & 867 & 1.035 & 889 & 600 & 684 & 2.383 & 3.329 \\
\hline & RN & 204 & 45 & 463 & 139 & 355 & 74 & 211 & 216 & 199 & 2.169 & - & 3.720 & 1.735 & 342 & 139 & 776 & 1.010 & 256 & 2.409 & 4.258 & 243 & 364 & 491 & 278 & 208 & 1.083 & 1.183 \\
\hline & PB & 320 & 42 & 78 & 204 & 422 & 120 & 154 & 533 & 349 & 1.973 & 4.893 & & 7.025 & 462 & 456 & 1.625 & 1.059 & 229 & 7.530 & 12.057 & 493 & 552 & 346 & 334 & 652 & 1.469 & 1.359 \\
\hline & PE & 291 & 88 & 978 & 298 & 1.202 & 103 & 506 & 1.426 & 1.238 & 4.121 & 2.941 & 8.848 & - & 6.157 & 1.364 & 7.781 & 2.647 & 563 & 5.742 & 29.357 & 1.024 & 1.284 & 664 & 908 & 1.448 & 2.217 & 1.788 \\
\hline & AL & 175 & 28 & 205 & 22 & 202 & 37 & 235 & 363 & 229 & 459 & 399 & 564 & 5.317 & - & 3.779 & 3.080 & 4.793 & 1.008 & 1.361 & 16.143 & 693 & 507 & 121 & 663 & 2.101 & 1.440 & 569 \\
\hline & SE & 101 & 0 & 42 & 29 & 151 & 4 & 100 & 129 & 170 & 210 & 211 & 257 & 533 & 2.116 & - & 4.763 & 879 & 295 & 1.087 & 4.942 & 223 & 218 & 165 & 104 & 147 & 240 & 533 \\
\hline & BA & 837 & 229 & 481 & 195 & 1.525 & 91 & 1.142 & 1.045 & 1.184 & 2.536 & 1.063 & 1.176 & 7.347 & 2.078 & 7.144 & & 14.077 & 14.120 & 9.607 & 65.151 & 2.377 & 2.795 & 1.492 & 926 & 1.392 & 11.167 & 6.498 \\
\hline & MG & 1.817 & 274 & 763 & 173 & 3.060 & 224 & 1.846 & 1.363 & 545 & 1.642 & 951 & 682 & 2.050 & 723 & 381 & 8.766 & 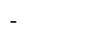 & 16.531 & 20.512 & 63.501 & 5.469 & 2.292 & 2.004 & 2.410 & 2.515 & 15.548 & 10.463 \\
\hline & ES & 835 & 24 & 141 & 23 & 353 & 64 & 65 & 221 & 139 & 217 & 86 & 59 & 264 & 121 & 89 & 4.608 & 10.091 & - & 7.564 & 3.633 & 527 & 395 & 324 & 242 & 283 & 593 & 537 \\
\hline & RJ & 603 & 221 & 3.331 & 317 & 2.458 & 219 & 478 & 2.029 & 846 & 5.655 & 4.722 & 7.254 & 5.131 & 1.132 & 1.479 & 7.053 & 21.740 & 11.056 & & 25.315 & 4.116 & 3.546 & 4.609 & 2.563 & 752 & 2.518 & 6.968 \\
\hline & SP & 2.961 & 602 & 1.758 & 338 & 3.609 & 348 & 1.982 & 4.748 & 7.915 & 15.565 & 6.393 & 10.460 & 21.188 & 7.736 & 4.844 & 39.341 & 66.424 & 5.497 & 20.914 & & 49.149 & 17.208 & 8.036 & 16.031 & 8.637 & 12.507 & 7.478 \\
\hline & PR & 2.564 & 235 & 711 & 248 & 1.311 & 111 & 710 & 597 & 153 & 717 & 358 & 359 & 588 & 169 & 183 & 2.269 & 4.707 & 625 & 2.629 & 37.403 & 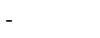 & 47.820 & 7.841 & 6.754 & 8.493 & 2.342 & 1.606 \\
\hline & SC & 975 & 85 & 252 & 148 & 386 & 71 & 146 & 245 & 114 & 475 & 330 & 279 & 568 & 298 & 53 & 878 & 1.589 & 325 & 1.902 & 9.371 & 22.396 & - & 15.401 & 1.273 & 2.232 & 1.319 & 1.452 \\
\hline & RS & 848 & 123 & 736 & 205 & 851 & 42 & 323 & 461 & 330 & 931 & 394 & 527 & 1.002 & 241 & 280 & 2.063 & 2.050 & 481 & 4.268 & 9.944 & 10.976 & 43.133 & & 2.096 & 3.169 & 1.533 & 2.352 \\
\hline & MS & 1.021 & 244 & 166 & 113 & 432 & 40 & 211 & 223 & 136 & 186 & 350 & 402 & 214 & 132 & 140 & 692 & 1.637 & 311 & 1.665 & 10.724 & 6.186 & 1.642 & 1.512 & - & 6.307 & 1.849 & 386 \\
\hline & MT & 6.321 & 344 & 849 & 91 & 3.532 & 116 & 1.088 & 948 & 442 & 362 & 236 & 134 & 373 & 341 & 180 & 874 & 2.112 & 539 & 849 & 6.543 & 7.033 & 2.811 & 1.831 & 5.901 & - & 8.970 & 1.142 \\
\hline & GO & 1.145 & 188 & 402 & 166 & 4.189 & 70 & 7.875 & 2.438 & 1.270 & 1.075 & 618 & 649 & 726 & 165 & 180 & 3.953 & 9.328 & 336 & 1.161 & 6.752 & 1.451 & 1.046 & 955 & 1.808 & 7.302 & - & 13.317 \\
\hline & DF & 163 & 126 & 646 & 212 & 1.130 & 143 & 2.022 & 2.873 & 3.345 & 2.422 & 1.125 & 1.719 & 1.384 & 486 & 486 & 3.752 & 6.715 & 801 & 4.268 & 5.771 & 1.334 & 1.146 & 1.676 & 402 & 648 & 38.762 & \\
\hline
\end{tabular}

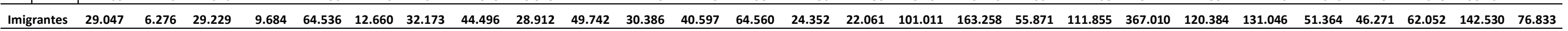

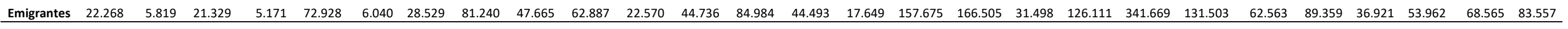

